\title{
Omissão de clíticos na aquisição bilingue português-espanhol ${ }^{1}$
}

\author{
Marina Cestari Nardelli \& Maria Lobo \\ Faculdade de Ciências Sociais e Humanas - Universidade NOVA de Lisboa/CLUNL
}

\begin{abstract}
:
This study examines clitic omission in Spanish-Portuguese bilingual acquisition. Using an elicited production task, we show that bilinguals omit clitics in both languages, but their rates of omission are higher in Portuguese. We show that, although bilinguals differ from monolinguals in their rates of omission in Spanish, they progressively become closer to monolinguals and like monolinguals they distinguish different syntactic contexts. This suggests that bilingual development is essentially similar to monolingual development but it is slower in what concerns syntactic properties for which the input may be ambiguous.
\end{abstract}

Keywords: acquisition, clitics, bilingualism, European Portuguese, Spanish.

Palavras-chave: aquisição, clíticos, bilinguismo, português europeu, espanhol.

\section{Introdução}

Neste trabalho, pretendemos contribuir para o conhecimento das características do desenvolvimento linguístico de crianças bilingues, comparando-o com o de crianças monolingues, através do estudo de um fenómeno que se sabe estar sujeito a variação interlinguística: a omissão de clíticos.

Com um estudo experimental de produção induzida de clíticos em crianças bilingues português europeu/espanhol ibérico e em crianças monolingues de português e monolingues de espanhol, procura-se determinar semelhanças e diferenças entre aquisição monolingue e bilingue e explorar fatores que condicionam a omissão de clíticos no processo de aquisição. $\mathrm{O}$ português e o espanhol, apesar de serem línguas tipologicamente próximas, apresentam diferenças relativamente aos contextos em que admitem omissão de clíticos e relativamente à colocação de clíticos, pelo que é relevante verificar em que medida há efeitos de influência de uma língua sobre a outra no processo de aquisição bilingue.

\footnotetext{
${ }^{1}$ Este trabalho foi financiado pela FCT, através do Projeto Estratégico PEst-OE/LIN/UI3213/2014.

Corresponde, em grande parte, ao trabalho desenvolvido pela primeira autora para a sua dissertação de mestrado (Nardelli 2015), orientado pela segunda autora.
} 


\section{Enquadramento}

\subsection{Aquisição bilingue vs. monolingue}

A questão de saber se a aquisição bilingue é semelhante à monolingue tem sido discutida na literatura. Vários autores têm defendido que, nos bilingues, há um desenvolvimento separado dos dois sistemas; os bilingues distinguem as duas línguas e atingem a mesma competência gramatical que os monolingues (Genesee 1989; Meisel 1989, 2004; De Houwer 2009; e.o.). Contudo, tem-se defendido também que, na aquisição bilingue, algumas áreas estão suscetíveis a processos de transferência, podendo haver efeitos de aceleração ou desaceleração (Paradis \& Genesee 1996). De acordo com Müller \& Hulk (2001), há determinadas áreas que estão particularmente vulneráveis: i) áreas que envolvem fenómenos de interface; e ii) áreas em que há ambiguidade ou sobreposição estrutural entre os dois sistemas.

Há também fatores extralinguísticos que podem desempenhar um papel no processo de aquisição bilingue, nomeadamente a quantidade de exposição a cada um dos sistemas e o facto de uma das línguas em aquisição ser dominante em relação à outra (Genesee, Nicoladis, Paradis 1995; Yip \& Matthews 2000).

Alguns autores defendem ainda que as próprias condições de aquisição bilingue, com um input reduzido em cada língua comparado com a aquisição monolingue, podem determinar um percurso diferenciado relativamente à aquisição monolingue; este efeito é referido, por vezes, como "efeito bilingue" (Pirvulescu et al. 2014).

Em súmula, é possível considerar que vários fatores podem desempenhar um papel no desenvolvimento bilingue, incluindo fatores intralinguísticos (características da estrutura das línguas em aquisição) e extralinguísticos (dominância linguística e exposição reduzida a input).

\subsection{Omissão de clíticos na aquisição monolingue}

Vários trabalhos têm mostrado que há diferenças entre línguas quanto à existência ou não de omissão de clíticos em fases iniciais de aquisição por crianças monolingues. A omissão está documentada num conjunto de línguas, incluindo o italiano (Schaeffer 1997, 2000), o francês (Jakubowicz et al. 1996), o catalão (Wexler, Gavarrò \& Torrens 2004; Gavarrò, Torrens \& Wexler 2010) e o português (Costa \& Lobo 2006; Silva 2008), mas não noutras, como o romeno (Babyonyshev \& Marin 2006), o serbo-croata (Ilic \& Deen 2004), o grego (Tsakali \& Wexler 2004) e o espanhol ibérico (Gavarrò, Torrens \& Wexler 2010). Há, contudo, alguma 
controvérsia relativamente a alguma desta evidência: Avram (1999) encontra omissão no romeno em dados de produção espontânea e Castilla \& Pérez-Leroux (2010) encontram omissão em variedades do espanhol americano. As discrepâncias entre estudos podem eventualmente ser atribuídas à natureza dos dados considerados (produção induzida vs. produção espontânea), à idade das crianças consideradas na amostra (geralmente inferior nos estudos que consideram produção espontânea) ou à variedade linguística considerada (há diferenças reconhecidas entre as diferentes variedades do espanhol).

Tsakali \& Wexler (2004) e Gavarrò, Torrens \& Wexler (2010) atribuíram as diferenças entre línguas quanto ao fenómeno de omissão na aquisição ao facto de as gramáticas iniciais estarem sujeitas a restrições quanto ao número de traços que um elemento pode verificar. Esta restrição é designada de Restrição de Verificação Única (Unique Checking Constraint) e estaria sujeita a maturação, desaparecendo por volta dos 4 anos de idade. Os autores explicam as diferenças entre línguas pelo facto de haver um mecanismo de verificação duplo apenas em línguas em que o clítico objeto concorda com o particípio passado, como acontece em italiano, catalão e francês. Assim, de acordo com esta hipótese, só haveria problemas para as gramáticas iniciais (e consequente omissão de clíticos) em línguas com concordância visível entre o particípio e o objeto.

A hipótese da Restrição de Verificação Única como fator explicativo da omissão enfrenta, contudo, problemas quando consideramos um conjunto de dados empíricos, como mostram Costa e Lobo (2006), entre outros: nem todas as línguas em que se verifica omissão manifestam concordância com o objeto (como é o caso do português) e a omissão pode prolongar-se muito para além dos 4 anos de idade, o que é difícil de conciliar com hipóteses de maturação. Para além disso, Varlokosta et al. (2016) mostram que o fenómeno de omissão não se restringe a línguas com clíticos: algumas línguas com pronomes fortes e fracos podem apresentar alguma taxa de omissão. Os autores defendem que a omissão pode ser o resultado de um fenómeno de generalização de construções com objeto nulo, mais expressivo em línguas em que há objetos nulos condicionados por fatores discursivos. Na mesma linha, Pérez-Leroux, Pirvulescu \& Roberge (2009) e Pirvulescu et al (2014) defendem que todas as línguas têm um estádio de omissão do objeto, que é resolvido a diferentes ritmos consoante as propriedades dos sistemas. Comparativamente com outras línguas, o português europeu, em que, como se sabe, está disponível uma construção de objeto nulo (Raposo 1986), é de facto a língua em que se 
verificam taxas mais altas de omissão e até idades mais tardias (Varlokosta et al. 2016). No português europeu, tal como descrito por Raposo (1986), a construção de objeto nulo é possível em frases simples, mas não em ilhas. Ora, as crianças portuguesas omitem clíticos também em ilhas. O teste do estudo de Varlokosta et al. (2016) incluía contextos de ilha adjunta (orações adverbiais causais). A omissão de clíticos neste contexto, que é um contexto ilegítimo de omissão, na aquisição do português europeu, pode assim ser tomada como um caso de generalização da construção de objeto nulo, como defendido por Costa \& Lobo (2006).

Para o português europeu, a hipótese de que a omissão corresponde a um tipo de omissão do objeto é apoiada por dados de compreensão. Costa \& Lobo (2009) mostram que, ao contrário da maioria dos adultos, as crianças aceitam interpretações transitivas para verbos sem objeto realizado em contextos ilegítimos na gramática adulta. Estes dados dão, assim, alguma sustentação à hipótese de que as crianças estão a sobregeneralizar os contextos em que o objeto nulo é legítimo.

A omissão do objeto nas gramáticas iniciais corresponderá então à opção por uma estrutura mais económica, disponível nas gramáticas das línguas humanas, estando a sua maior ou menor expressão na aquisição de diferentes línguas dependente da maior ou menor evidência, nos diferentes sistemas linguísticos, de que é possível algum tipo de omissão de objeto (Varlokosta et al. 2016). De acordo com Pérez-Leroux, Pirvulescu \& Roberge (2008) e Pirvulescu et al. (2014), o objeto nulo corresponde a uma possibilidade estrutural por defeito, que estará dependente de propriedades lexicais; nos bilingues, o desenvolvimento é mais lento precisamente porque está dependente do desenvolvimento lexical e o desenvolvimento lexical exige uma maior quantidade de input.

\subsection{Omissão de clíticos na aquisição bilingue}

$\mathrm{Na}$ aquisição bilingue, vários estudos têm considerado a influência das propriedades das línguas em aquisição no desenvolvimento de cada um dos sistemas, procurando verificar se há influência de uma língua sobre a outra, qual a direcionalidade dessa influência ou se há distinção clara entre os dois sistemas.

Especificamente no que diz respeito à aquisição de pronomes, alguns estudos baseados em dados de produção espontânea mostram que pode haver alguma interferência de uma língua 
sobre a outra. O estudo de Serratrice, Sorace \& Paoli (2004), baseado nas produções de uma criança bilingue italiano-inglês, línguas em que não está disponível a construção de objeto nulo e que se distinguem quanto ao tipo de pronome (clítico em italiano e forte em inglês), identificou produção de pronomes fortes em italiano, mas não encontrou omissão do objeto em nenhuma das línguas. O estudo de Yip \& Matthews (2005), baseado em 5 crianças bilingues cantonês-inglês, línguas que diferem quanto à disponibilidade de objeto nulo (existente em cantonês, mas não em inglês), identificou uma maior omissão de objeto nas produções em inglês dos bilingues, quando comparadas com as dos monolingues, fenómeno que os autores atribuem a uma transferência do cantonês. O estudo de Stöber \& Meisel (2008) baseia-se nas produções de 2 crianças bilingues português do Brasil-alemão. O português do Brasil é uma língua que admite objeto nulo (inclusive em contextos de ilha) e o alemão é uma língua que aceita a queda de tópicos ('topic drop'), permitindo, portanto, omissões de argumentos em contextos específicos. Os autores concluem que as crianças estudadas distinguem os dois sistemas.

Nos estudos que usam metodologias experimentais e em particular tarefas de produção induzida, tem-se mostrado haver omissão nas crianças bilingues superior à dos monolingues. Costa, Lobo \& Pratas (2013, 2014) estudam o fenómeno num grupo de bilingues caboverdiano/português europeu (PE). O PE, como é sabido, é uma língua que aceita objetos nulos, mas não em contexto de ilha (Raposo, 1986); em cabo-verdiano, pelo contrário, a produção do clítico objeto é obrigatória. Neste estudo, verificou-se que há omissão nos bilingues em caboverdiano muito superior à dos monolingues de cabo-verdiano e que a omissão em português é correspondente à que se encontra para os monolingues de PE, que, como se sabe omitem clíticos em taxas altas e até mais tarde do que noutras línguas (Costa \& Lobo 2006, Silva 2008; Varlokosta et al. 2016). O estudo de Pirvulescu et al. (2014) considera um grupo de bilingues inglês-francês, línguas que não são de objeto nulo e em que a omissão de objeto é meramente residual na gramática adulta. Apesar de estas línguas não permitirem objeto nulo, verificou-se uma maior omissão nos bilingues do que nos monolingues em ambas as línguas. De acordo com os autores, este efeito pode ser atribuído à opção pela forma mais defetiva ("efeito bilingue"): face a um input potencialmente ambíguo, em que algumas estruturas sem realização de objeto são possíveis, as crianças optam pela forma mais defetiva, recorrendo a uma representação 'default' de objeto nulo, disponível na gramática universal. Nos bilingues, a 
determinação dos tipos de objetos sem realização fonética teria um desenvolvimento mais lento do que nos monolingues.

Para além da hipótese de que as crianças tendem a optar pela forma com menores custos computacionais, uma outra causa possível para a omissão de clíticos discutida em alguns dos trabalhos é estarmos perante um efeito atribuível a uma maior exposição à língua dominante e corresponder, por conseguinte, a um fenómeno de transferência.

\subsection{Clíticos e objeto nulo no português e no espanhol}

O que torna a investigação sobre bilingues português europeu-espanhol interessante?

O português e o espanhol são duas línguas tipologicamente próximas, que partilham muitas propriedades gramaticais. Distinguem-se, contudo, quanto aos contextos em que a omissão do objeto é possível. No português europeu, de acordo com Raposo (1986), o objeto pode ser omitido quando tem traços de terceira pessoa, é recuperável no contexto discursivo e não se encontra no interior de ilhas sintáticas (domínios que bloqueiam a extração de constituintes). Assim, o apagamento do objeto (a par da realização do clítico) é possível em (1), mas não em (2). Para além disso, os reflexos não permitem a omissão: ${ }^{2}$

(1) - Onde guardaste a chave?

- Guardei(-a) na gaveta.

(2) O João não encontra a chave porque eu *(a) guardei na gaveta.

(3) O Pedro lavou*(-se)

Estas restrições à ocorrência de objeto nulo levaram Raposo (1986) a propor que o objeto nulo do português europeu é uma categoria vazia do tipo 'variável', isto é, uma categoria vazia coindexada com um operador tópico nulo num domínio não argumental periférico. Isso explicaria a impossibilidade de objeto nulo em ilhas sintáticas.

\footnotetext{
${ }^{2}$ Ver também Duarte e Costa (2013) para uma descrição das propriedades da construção de objeto nulo. 
O espanhol peninsular, em geral, é muito mais restritivo quanto aos contextos em que permite apagamento do clítico. ${ }^{3}$ De acordo com Campos (1986), apenas é permitido o apagamento do objeto quando este é indefinido (4), mas não quando é definido (5):

(4) - ¿Compraste libros?

- Sí, compré.

(5) - ¿Compraste los libros?

- Sí, *(los) compré.

As duas línguas divergem ainda quanto aos padrões de colocação de clíticos. Em espanhol há próclise em orações finitas e ênclise em não finitas, ao passo que no português europeu encontramos variação entre ênclise e próclise em orações finitas em função de diferentes elementos desencadeadores de próclise (Martins 2013).

A produção de clíticos é, pois, uma área em que há diferenças entre os dois sistemas linguísticos e que pode constituir uma área de transferência no desenvolvimento bilingue.

\section{Estudo}

\subsection{Relevância do estudo e questões de investigação}

Tendo em conta que a aquisição bilingue português europeu/espanhol ibérico é uma combinação pouco estudada e que estas duas línguas, apesar de tipologicamente próximas, diferem quanto aos contextos de omissão do objeto, procurámos verificar de que forma isso condicionaria as produções dos bilingues. Como referimos no enquadramento teórico, a produção de clíticos é uma área em que, de acordo com Müller \& Hulk (2001), pode haver transferência entre sistemas linguísticos, na medida em que é uma área da gramática que envolve a interface sintaxe-pragmática e em que há alguma sobreposição entre os dois sistemas (português e espanhol, neste caso).

\footnotetext{
${ }^{3}$ Em algumas zonas, como é o caso do espanhol falado no País Basco, pode encontrar-se mais omissão, explicável pela influência do basco (García Mouton 1994).
} 
Para além disso, o contexto sociolinguístico dos participantes bilingues considerados no nosso estudo difere do dos participantes bilingues cabo-verdiano-português considerados em Costa, Lobo e Pratas $(2013,2014)$. Apesar de, em ambos os casos, termos uma língua de objeto nulo (o português) e uma língua sem a possibilidade de omissão em contextos definidos, como os de (1) (cabo-verdiano ou espanhol) e de, em ambos os casos, os participantes estarem a residir em Portugal, o contexto de escolarização e de prestígio social da segunda língua é diferente: no nosso estudo, os participantes frequentavam uma escola em que o ensino é feito maioritariamente em espanhol, sendo o espanhol uma língua de prestígio reconhecido; o caboverdiano ainda se encontra numa situação de desigualdade relativamente ao português, tendo geralmente menos prestígio e carecendo de ensino formal.

Tendo isto em consideração, colocámos as seguintes questões de investigação:

a) O percurso de desenvolvimento dos falantes bilingues é semelhante ao dos monolingues (no que respeita à produção de clíticos)?

b) Os falantes bilingues distinguem os dois sistemas?

c) Os falantes bilingues são suscetíveis a fenómenos de transferência?

d) Se sim, em que sentido? Há efeitos de aceleração - menor omissão em PE comparativamente aos monolingues? Há efeitos de desaceleração - maior omissão em espanhol comparativamente aos monolingues?

e) Os falantes bilingues são sensíveis aos contextos morfossintáticos em que o objeto nulo é legítimo, i.e., há diferenças na produção de clíticos acusativos em frases simples, clíticos reflexos em frases simples e clíticos acusativos em ilhas?

\subsection{Metodologia}

\subsubsection{Participantes}

Participaram no teste um total de 187 sujeitos, cujas características são apresentadas na seguinte tabela: 


\begin{tabular}{|l|c|c|c|c|c|c|c|c|c|}
\cline { 2 - 10 } \multicolumn{1}{c|}{} & \multicolumn{3}{c|}{ Monolingues PE } & \multicolumn{3}{c|}{ Monolingues EI } & \multicolumn{3}{c|}{ Bilingues PE/EI } \\
\cline { 2 - 10 } \multicolumn{1}{c|}{} & $\mathrm{N}^{\mathbf{o}}$ & Intervalo & $\begin{array}{c}\text { Média } \\
\text { idade }\end{array}$ & $\mathrm{N}^{\mathbf{o}}$ & Intervalo & $\begin{array}{c}\text { Média } \\
\text { idade }\end{array}$ & $\mathrm{N}^{\mathbf{o}}$ & Intervalo & $\begin{array}{c}\text { Média } \\
\text { idade }\end{array}$ \\
\hline 3 anos & -- & -- & -- & 15 & $3 ; 2-3 ; 11$ & $3 ; 6$ & 21 & $3 ; 0-3 ; 11$ & $3 ; 7$ \\
\hline $\mathbf{4}$ anos & 20 & $4 ; 1-4 ; 11$ & $4 ; 6$ & 14 & $4 ; 0-4 ; 10$ & $4 ; 8$ & 21 & $4 ; 0-4 ; 11$ & $4 ; 8$ \\
\hline $\mathbf{5}$ anos & 20 & $5 ; 0-5 ; 10$ & $5 ; 4$ & 15 & $5 ; 0-5 ; 11$ & $5 ; 4$ & 17 & $5 ; 5-5 ; 11$ & $5 ; 9$ \\
\hline adultos & 21 & $18-38$ & $21 ; 1$ & 12 & $25-60$ & $42 ; 6$ & 11 & $25-32$ & $28 ; 8$ \\
\hline
\end{tabular}

Tabela 1. Participantes

Os bilingues residiam em Portugal na zona de Lisboa. Tratava-se maioritariamente de bilingues simultâneos, com as duas línguas faladas em casa ${ }^{4}$. As crianças frequentavam o Instituto Espanhol. Estavam, pois, inseridas num contexto nacional em que a língua portuguesa é dominante, mas num contexto em que a escolarização é feita maioritariamente em espanhol.

Os monolingues de espanhol eram residentes em Espanha na cidade de Madrid e frequentavam uma escola de ensino particular. As crianças eram nascidas em Madrid e filhas de pais madrilenos.

As crianças monolingues portuguesas eram residentes na zona da grande Lisboa e frequentavam infantários de diferentes instituições particulares de solidariedade social (IPSS).

Uma vez que o teste foi aplicado aos bilingues em duas versões (portuguesa e espanhola), obtiveram-se resultados de um total de 257 testes.

\subsubsection{Teste}

Aplicámos um teste de produção induzida que favorecia a produção de clíticos de $3^{\mathrm{a}}$ pessoa singular com a ajuda de imagens, semelhante ao que foi aplicado em estudos anteriores (Varlokosta et al. 2016). O teste contemplava três condições, correspondendo a três contextos sintáticos distintos: i) clíticos não reflexos em frases simples (12 itens); ii) clíticos não reflexos em ilhas adjuntas (orações adverbiais causais) (12 itens); iii) clíticos reflexos em frases simples (10 itens), contando com um total de 34 itens, para além dos itens de treino. Os contextos

\footnotetext{
${ }^{4}$ Foram incluídas também 4 crianças bilingues precoces, cuja exposição à segunda língua foi feita antes da entrada no pré-escolar, duas incluídas no grupo dos três anos, uma incluída no grupo dos quatro anos e uma no grupo dos 5 anos.
}

№ 3 - 09/ 2017 | 241-263 | https://doi.org/ 10.26334/2183-9077/rapln3ano2017a14 249 
contemplavam todos objetos definidos. A ordem de apresentação dos itens foi aleatorizada (ver Anexo 1).

A inclusão destes três contextos permite verificar se há uma distinção entre os contextos em que a omissão é legítima em PE (como o de clíticos não reflexos em frases simples) e os contextos em que a omissão não é permitida na gramática adulta (como os de clíticos reflexos e contextos de ilha). No caso do espanhol, a omissão não deverá ser permitida em nenhum dos casos, uma vez que o teste só continha contextos definidos.

O teste foi aplicado aos monolingues de português na versão portuguesa, aos monolingues de espanhol na versão espanhola e aos bilingues nas duas versões. Neste caso, aplicou-se primeiro a versão em espanhol e só mais tarde a versão em português. Foi tomada a decisão de aplicar primeiro a versão em espanhol para evitar que a omissão possível em português pudesse ter influência sobre a produção em espanhol, tal como aconteceu em Costa, Lobo e Pratas $(2013,2014)$.

Foram usados verbos que tivessem propriedades sintáticas semelhantes nas duas línguas, podendo funcionar como transitivos diretos.

Foi mostrada ao participante uma imagem num computador e feita uma pergunta.

Damos um exemplo de item usado para cada uma das condições.

Condição 1 - Clítico acusativo frase simples

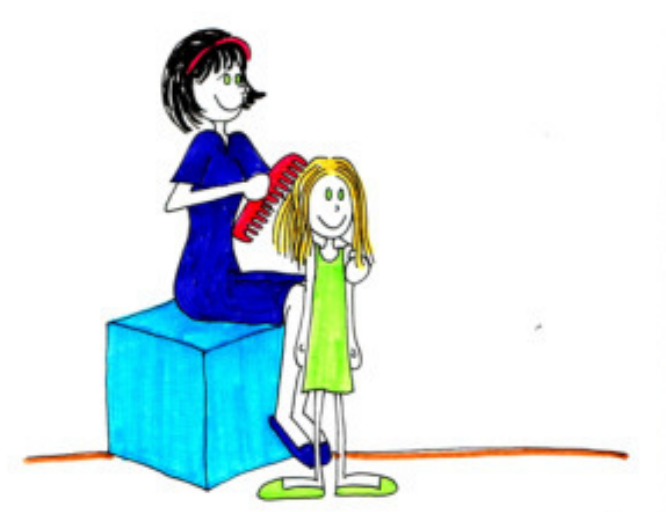

Imagem 1. Imagem associada a frase teste de condição clítico acusativo em frase simples 
(6) Versão portuguesa:

Investigador: $\quad$ Temos aqui uma mãe e uma filha.

O que é que a mãe está a fazer à filha?

Resposta esperada: Está a penteá-la. /Está a pentear [-].

Versão espanhola:

Investigador: $\quad$ Aquí tenemos a una mamá y a una hija.

¿Qué le está haciendo la mamá a la hija?

Resposta esperada: La está peinando.

Condição 2 - Clítico acusativo em ilha (adjunta)

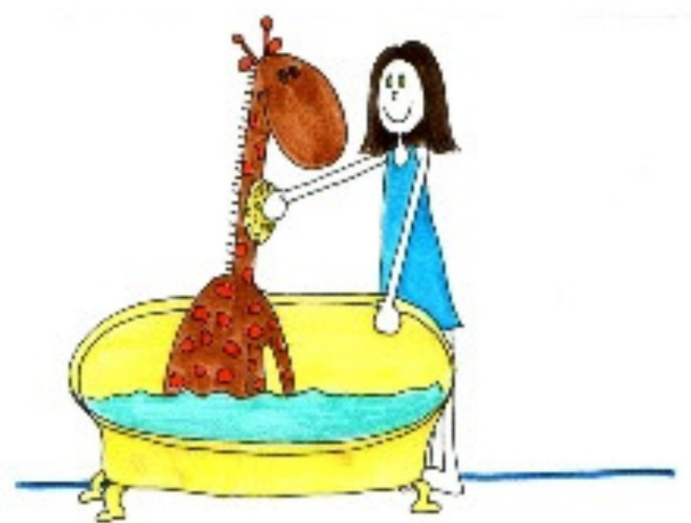

Imagem 2. Exemplo de imagem usada para a condição de clítico acusativo em ilha (adjunta)

(7) Versão portuguesa:

Investigador: $\quad$ A menina lavou a girafa e a girafa ficou limpa.

Porque é que a girafa ficou limpa?

A girafa ficou limpa porque a menina....

Resposta esperada: ...a limpou.

Versão espanhola:

Investigador: $\quad$ La chica ha lavado a la jirafa y la jirafa se ha quedado limpia. 
¿Por qué se ha quedado limpia la jirafa?

La jirafa se ha quedado limpia porque la niña...

Resposta esperada: ...la ha limpiado/la limpió.

Condição 3 - Clítico reflexo

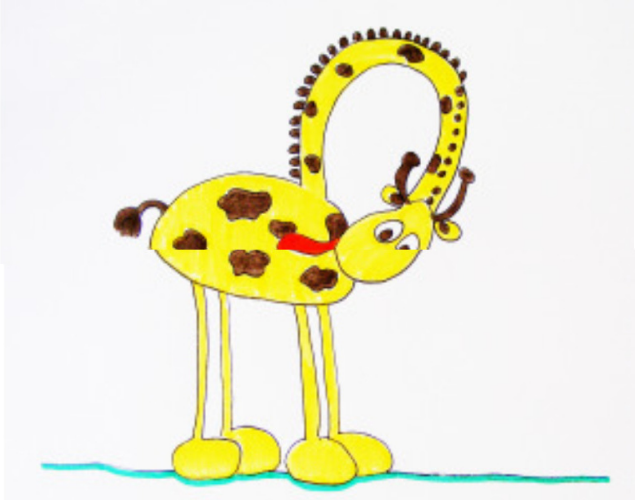

Imagem 3. Imagem usada na condição de clítico reflexo

(8) Versão portuguesa:

Investigador: $\quad$ Temos aqui uma girafa.

O que é que a girafa está a fazer?

Resposta esperada: Está a lamber-se.

Versão espanhola:

Investigador: Aquí tenemos una jirafa.

¿Qué está haciendo la jirafa?

Resposta esperada: Se está lamiendo.

\subsubsection{Codificação de respostas}

As respostas obtidas foram codificadas, tendo-se considerado os seguintes tipos de respostas: 
a) Produção de clítico alvo - considerou-se como alvo a produção de clítico acusativo ou dativo típico de 'leísmo' nas condições com acusativo ${ }^{6}$ e de clítico reflexo nas condições com reflexo

b) Omissão

c) Produção de pronome forte

d) Produção de grupo nominal pleno

e) Outra resposta - considerou-se nesta categoria a produção de um clítico não alvo (e.g. reflexo nas condições de acusativo) ou a produção de outra estrutura (e.g. uso de verbo intransitivo ou ditransitivo).

\subsection{Resultados}

Apresentamos de seguida os resultados obtidos por condição em cada um dos grupos.

Na tabela 2, podem observar-se os resultados da Condição de clíticos acusativos em frases simples:

\begin{tabular}{|l|c|c|c|c|c|c|c|c|c|c|}
\cline { 2 - 11 } \multicolumn{1}{c|}{} & \multicolumn{4}{|c|}{ Monolingues português } & \multicolumn{5}{c|}{ Bilingues em português } \\
\cline { 2 - 12 } & Clítico & nulo & pron. & DP & outro & clítico & nulo & pron. & DP & outro \\
\hline $\mathbf{3}$ anos & -- & -- & -- & -- & -- & $22,2 \%$ & $\mathbf{5 1 , 6 \%}$ & 0 & $5,2 \%$ & $21 \%$ \\
\hline $\mathbf{4}$ anos & $22 \%$ & $\mathbf{5 4 , 2 \%}$ & $1,7 \%$ & $8,3 \%$ & $13,8 \%$ & $27,8 \%$ & $\mathbf{4 9 , 6 \%}$ & 0 & $4,8 \%$ & $17,8 \%$ \\
\hline $\mathbf{5}$ anos & $42,9 \%$ & $\mathbf{4 5 \%}$ & $2,9 \%$ & $2 \%$ & $7 \%$ & $16,7 \%$ & $\mathbf{5 7 , 8 \%}$ & $1,5 \%$ & $7,3 \%$ & $16,7 \%$ \\
\hline adultos & $73,8 \%$ & $\mathbf{4 , 8 \%}$ & 0 & $20,2 \%$ & $1,2 \%$ & $81,8 \%$ & $\mathbf{1 0 , 6 \%}$ & 0 & $5,3 \%$ & $2,3 \%$ \\
\hline & \multicolumn{4}{|c|}{ Monolingues espanhol } & \multicolumn{5}{c|}{ Bilingues em espanhol } \\
\cline { 2 - 12 } & Clítico & nulo & pron. & DP & Outro & clítico & nulo & pron. & DP & outro \\
\hline $\mathbf{3}$ anos & $56,7 \%$ & $\mathbf{2 3 , 9 \%}$ & 0 & $1,1 \%$ & $18,3 \%$ & $19,9 \%$ & $\mathbf{5 2 , 6 \%}$ & 0 & $5,2 \%$ & $22,3 \%$ \\
\hline $\mathbf{4}$ anos & $78,6 \%$ & $\mathbf{8 , 3 \%}$ & $0,6 \%$ & $2,3 \%$ & $10,1 \%$ & $26,6 \%$ & $\mathbf{5 5 , 1 \%}$ & $0,4 \%$ & $3,2 \%$ & $14,7 \%$ \\
\hline $\mathbf{5}$ anos & $72,8 \%$ & $\mathbf{1 8 , 9 \%}$ & 0 & $1,1 \%$ & $7,2 \%$ & $53,5 \%$ & $\mathbf{2 7 , 5 \%}$ & $2,9 \%$ & $2,9 \%$ & $13,2 \%$ \\
\hline adultos & $86,1 \%$ & $\mathbf{7 , 2 \%}$ & 0 & $0,7 \%$ & $6,9 \%$ & $91,6 \%$ & $\mathbf{5 , 3 \%}$ & 0 & $1,5 \%$ & $1,5 \%$ \\
\hline
\end{tabular}

Tabela 2. Resultados Condição clíticos acusativos em frase simples

\footnotetext{
${ }^{6} \mathrm{O}$ 'leismo' é um fenómeno generalizado no espanhol. Embora haja diferentes tipos de 'leísmo', com distribuições geográficas diversas (cf. Fernández-Ordoñez 1999, 2012), o ‘leísmo’ em que um acusativo masculino humano é substituído por um dativo é comum mesmo na variedade padrão do espanhol (Fernández-Ordoñez 2012).
} 
Nesta condição, os bilingues em espanhol têm taxas de omissão superiores à dos monolingues em espanhol e próximas das dos monolingues em português, tal como seria de esperar tendo em conta os resultados de estudos anteriores (Costa \& Lobo 2006; Silva 2008; Costa, Lobo \& Pratas 2013, 2014; entre outros). A taxa de omissão dos bilingues em espanhol reduz-se na faixa etária dos 5 anos. Repare-se que, apesar de haver omissão, todos os grupos produzem clíticos. Os monolingues de espanhol têm alguma omissão, mas em taxas muito inferiores às dos bilingues. Note-se que as taxas de omissão que encontramos nos monolingues espanhóis são mais altas do que as que estão relatadas para outros estudos. Voltaremos a esta questão.

Vejamos agora os resultados obtidos na condição com clíticos em ilha:

\begin{tabular}{|l|l|l|l|l|l|l|l|l|l|l|}
\cline { 2 - 11 } \multicolumn{1}{c|}{} & \multicolumn{4}{c|}{ Monolingues português } & \multicolumn{5}{c|}{ Bilingues em português } \\
\cline { 2 - 12 } \multicolumn{1}{c|}{ clítico } & nulo & pron. & DP & outro & clítico & nulo & pron. & DP & outro \\
\hline $\mathbf{3}$ anos & -- & -- & -- & -- & -- & $24,2 \%$ & $\mathbf{6 0 , 7 \%}$ & $0,4 \%$ & $1,6 \%$ & $13,1 \%$ \\
\hline $\mathbf{4}$ anos & $15,4 \%$ & $\mathbf{4 2 \%}$ & $4,2 \%$ & $2,5 \%$ & 35,9 & $38,1 \%$ & $\mathbf{4 8 , 4 \%}$ & $0,8 \%$ & $2,8 \%$ & $9,9 \%$ \\
\hline $\mathbf{5}$ anos & $33,8 \%$ & $\mathbf{3 5 \%}$ & $2,9 \%$ & $3,8 \%$ & $24,6 \%$ & $35,3 \%$ & $\mathbf{4 5 , 1 \%}$ & $3,9 \%$ & $4,4 \%$ & $11,3 \%$ \\
\hline adultos & $61,9 \%$ & $\mathbf{0}$ & 0 & $16,3 \%$ & $21,8 \%$ & $91,7 \%$ & $\mathbf{3 , 8 5}$ & 0 & $3,8 \%$ & $0,7 \%$ \\
\hline & \multicolumn{4}{|c|}{ Monolingues espanhol } & \multicolumn{5}{c|}{ Bilingues em espanhol } \\
\cline { 2 - 12 } & clítico & nulo & pron. & DP & Outro & clítico & nulo & pron. & DP & Outro \\
\hline $\mathbf{3}$ anos & $86,1 \%$ & $\mathbf{3 , 3 \%}$ & 0 & $0,6 \%$ & $10 \%$ & $59,5 \%$ & $\mathbf{2 1 \%}$ & $0,4 \%$ & $0,4 \%$ & $18,7 \%$ \\
\hline $\mathbf{4}$ anos & $92,9 \%$ & $\mathbf{3 \%}$ & 0 & 0 & $4,1 \%$ & $61,9 \%$ & $\mathbf{2 4 , 6 \%}$ & $0,4 \%$ & $1,6 \%$ & $11,5 \%$ \\
\hline $\mathbf{5}$ anos & $93,3 \%$ & $\mathbf{2 , 8 \%}$ & 0 & $0,6 \%$ & $3,3 \%$ & $76 \%$ & $\mathbf{1 1 , 8 \%}$ & $3,4 \%$ & 0 & $8,8 \%$ \\
\hline adultos & $96,5 \%$ & $\mathbf{0}$ & 0 & $1,4 \%$ & $2,1 \%$ & $99,2 \%$ & $\mathbf{0 , 8 \%}$ & 0 & 0 & 0 \\
\hline
\end{tabular}

Tabela 3. Resultados Condição clíticos acusativos em ilha

Nesta condição, as taxas de omissão quer nos monolingues de português, quer nos bilingues em português são ainda bastante altas, contrastando claramente com as taxas de omissão que se encontram em espanhol. Os monolingues de espanhol têm apenas omissão residual, ao passo que os bilingues têm taxas de omissão mais elevadas, mas inferiores às que se encontram em português. $\mathrm{O}$ grupo dos bilingues de 5 anos já tem uma taxa de omissão reduzida em espanhol (11,8\%), o que mostra que há desenvolvimento dos 4 para os 5 anos.

Na tabela 4, apresentamos os resultados obtidos na condição com reflexos 


\begin{tabular}{|l|l|l|l|l|l|l|l|l|l|l|}
\cline { 2 - 11 } \multicolumn{1}{c|}{} & \multicolumn{4}{c|}{ Monolingues português } & \multicolumn{5}{c|}{ Bilingues em português } \\
\cline { 2 - 12 } \multicolumn{1}{c|}{} & clítico & nulo & pron. & DP & outro & clítico & Nulo & pron. & DP & outro \\
\hline $\mathbf{3}$ anos & -- & -- & -- & -- & -- & $50 \%$ & $\mathbf{2 1 , 4 \%}$ & 0 & 0 & $28,6 \%$ \\
\hline $\mathbf{4}$ anos & $41,5 \%$ & $\mathbf{2 7} \%$ & $1 \%$ & $1 \%$ & $29,5 \%$ & $49,5 \%$ & $\mathbf{2 1 , 9 \%}$ & 0 & 0 & $28,6 \%$ \\
\hline $\mathbf{5}$ anos & $68,5 \%$ & $\mathbf{1 4 \%}$ & $0,5 \%$ & $1 \%$ & $16 \%$ & $52,9 \%$ & $\mathbf{2 5 , 9 \%}$ & $0,6 \%$ & 0 & $20,6 \%$ \\
\hline adultos & $91,4 \%$ & $\mathbf{0 , 9 5 \%}$ & 0 & $0,95 \%$ & $6,7 \%$ & $96,4 \%$ & $\mathbf{0}$ & 0 & 0 & $3,6 \%$ \\
\hline & \multicolumn{6}{|c|}{ Monolingues espanhol } \\
\cline { 2 - 13 } & clítico & nulo & pron. & DP & outro & clítico & Nulo & pron. & DP & outro \\
\hline $\mathbf{3}$ anos & $74 \%$ & $\mathbf{6 \%}$ & 0 & 0 & $20 \%$ & $50 \%$ & $\mathbf{2 1 , 4 \%}$ & 0 & 0 & $28,6 \%$ \\
\hline $\mathbf{4}$ anos & $89,3 \%$ & $\mathbf{2 , 9 \%}$ & 0 & 0 & $7,9 \%$ & $45,2 \%$ & $\mathbf{2 8 , 1 \%}$ & 0 & 0 & $26,7 \%$ \\
\hline $\mathbf{5}$ anos & $85,3 \%$ & $\mathbf{5 , 3 \%}$ & 0 & 0 & $9,3 \%$ & $72,4 \%$ & $\mathbf{1 2 , 9 \%}$ & 0 & 0 & $14,7 \%$ \\
\hline adultos & $95 \%$ & $\mathbf{0}$ & 0 & 0 & $5 \%$ & $98,2 \%$ & $\mathbf{0}$ & 0 & 0 & $1,8 \%$ \\
\hline
\end{tabular}

Tabela 4. Resultados Condição clíticos reflexos

Como se pode observar, no grupo de crianças monolingues portuguesas, também há omissão neste contexto, mas em taxas inferiores às que se encontram com clíticos acusativos. Estes resultados confirmam os de Silva (2008), que mostra que o contexto em que a omissão de clíticos desaparece mais cedo é o de clíticos reflexos. O grupo dos bilingues tem taxas aproximadas de omissão em português. Em espanhol, a omissão é apenas residual nos monolingues, contrastando com o que acontece nos bilingues em espanhol, em que as taxas de omissão são mais altas.

Se compararmos as taxas de omissão globais nos bilingues em cada uma das línguas (Tabela 5), verificamos que, apesar de haver omissão em espanhol, há diferenças entre os dois sistemas que se manifestam de forma mais notória no contexto de ilhas: as taxas de omissão em português são superiores às que se encontram em espanhol:

\begin{tabular}{|l|c|c|c|c|c|c|}
\cline { 2 - 7 } \multicolumn{1}{c|}{} & \multicolumn{3}{c|}{ Bilingues em português } & \multicolumn{3}{c|}{ Bilingues em espanhol } \\
\cline { 2 - 7 } \multicolumn{1}{c|}{} & $\begin{array}{c}\text { Acusativo } \\
\text { frase } \\
\text { simples }\end{array}$ & $\begin{array}{c}\text { Acusativo } \\
\text { ilha }\end{array}$ & Reflexo & $\begin{array}{c}\text { Acusativo } \\
\text { frase } \\
\text { simples }\end{array}$ & $\begin{array}{c}\text { Acusativo } \\
\text { ilha }\end{array}$ & Reflexo \\
\hline $\mathbf{3}$ anos & $51,6 \%$ & $60,7 \%$ & $21,4 \%$ & $52,6 \%$ & $21 \%$ & $21,4 \%$ \\
\hline $\mathbf{4}$ anos & $49,6 \%$ & $48,4 \%$ & $21,9 \%$ & $55,1 \%$ & $24,6 \%$ & $28,1 \%$ \\
\hline $\mathbf{5}$ anos & $57,8 \%$ & $45,1 \%$ & $25,9 \%$ & $27,5 \%$ & $11,8 \%$ & $12,9 \%$ \\
\hline adultos & $10,6 \%$ & $3,8 \%$ & 0 & $5,3 \%$ & $0,8 \%$ & 0 \\
\hline
\end{tabular}

Tabela 5. Taxas de omissão nos bilingues em cada condição 
Nas crianças de 5 anos, a diferença entre os dois sistemas é mais visível, havendo taxas inferiores de omissão relativamente às produções em português em todas as condições. No grupo dos adultos, a omissão é residual ou nula nos contextos em que o objeto nulo não está disponível na gramática.

Como referimos acima, as taxas de omissão encontradas no nosso estudo no grupo de controlo de monolingues de espanhol foram superiores às que estão relatadas para outros estudos (Gavarrò, Torrens \& Wexler 2010; Gavarrò \& Fortón 2014). ${ }^{7}$ Ainda que seja possível pensar que estas taxas reduzidas de omissão em espanhol se podem também dever ao facto de, em espanhol, as crianças terem de determinar quais os contextos legítimos de objeto nulo, distinguindo contextos definidos e indefinidos, estas taxas são superiores às que foram encontradas noutros trabalhos com crianças monolingues de espanhol. Decidimos, assim, verificar se as maiores taxas de omissão encontradas no nosso estudo estavam relacionadas com a produção de formas não finitas, isto é, se as taxas de omissão seriam diferentes se considerássemos apenas as produções em que a forma verbal é claramente finita e puséssemos de parte as formas não finitas (e.g. lavar ou lavando). Na Tabela 6., apresentamos as taxas de omissão considerando apenas omissão os casos em que o participante produziu formas verbais finitas (e.g. está lavando; lavou):

\begin{tabular}{|l|c|c|c|c|c|c|c|c|c|}
\cline { 2 - 10 } \multicolumn{1}{c|}{} & \multicolumn{2}{|c|}{ Monolingues espanhol } & \multicolumn{3}{c|}{ Bilingues espanhol } & \multicolumn{3}{c|}{ Bilingues português } \\
\cline { 2 - 10 } & $\begin{array}{c}\text { Acus. } \\
\text { frase } \\
\text { simples }\end{array}$ & $\begin{array}{c}\text { Acus. } \\
\text { Ilha }\end{array}$ & Refl. & $\begin{array}{c}\text { Acus. } \\
\text { frase } \\
\text { simples }\end{array}$ & $\begin{array}{c}\text { Acus. } \\
\text { ilha }\end{array}$ & Refl. & $\begin{array}{c}\text { Acus. } \\
\text { frase } \\
\text { simples }\end{array}$ & $\begin{array}{c}\text { Acus. } \\
\text { ilha }\end{array}$ & Refl. \\
\hline $\mathbf{3}$ anos & $3,9 \%$ & $2,8 \%$ & $1,3 \%$ & $21,9 \%$ & $18,7 \%$ & $11,9 \%$ & $32,5 \%$ & $60,7 \%$ & $11 \%$ \\
\hline $\mathbf{4}$ anos & $2,4 \%$ & $3 \%$ & $0 \%$ & $16,3 \%$ & $23,4 \%$ & $8,6 \%$ & $12,3 \%$ & $48,4 \%$ & $4,3 \%$ \\
\hline $\mathbf{5}$ anos & 0 & $1,4 \%$ & 0 & $8,3 \%$ & $10,8 \%$ & $5,3 \%$ & $20,1 \%$ & $45,1 \%$ & $5,9 \%$ \\
\hline adultos & $0,7 \%$ & 0 & 0 & $1,3 \%$ & $0,6 \%$ & 0 & $2,3 \%$ & $3,8 \%$ & 0 \\
\hline
\end{tabular}

Tabela 6. Taxas de omissão considerando apenas formas verbais finitas

Verificámos que as formas de progressivo (induzidas na condição de acusativo em frase simples e na condição de reflexo) favorecem a produção de formas não finitas, que facilitam a omissão. A condição de ilha induzia o pretérito e deu origem a um menor número de formas

\footnotetext{
${ }^{7}$ Gavarrò \& Fortón (2014: 106) reportam que a omissão foi mais frequente com verbos não finitos do que com verbos finitos.
}

№ 3 - 09/ 2017 | 241-263 | https://doi.org/ 10.26334/2183-9077/rapln3ano2017a14 256 
não finitas. Com esta alteração, as taxas de omissão nos monolingues tornam-se residuais e correspondentes às que foram encontradas em trabalhos anteriores para o espanhol (inferiores a 4\%). Nos bilingues, mantêm-se taxas mais elevadas de omissão, com uma diferença clara entre os contextos de reflexos e os contextos que induziam clíticos acusativos. Há, por conseguinte, um efeito do tempo verbal produzido, que deve ser tido em conta na análise dos resultados.

\section{Discussão e conclusões}

Retomemos agora as questões de investigação que enunciámos acima e vejamos quais as conclusões a que o nosso estudo permitiu chegar.

Os falantes bilingues são suscetíveis a fenómenos de transferência? Se sim, em que sentido? Há efeitos de aceleração - menor omissão em PE comparativamente aos monolingues? Há efeitos de desaceleração - maior omissão em espanhol comparativamente aos monolingues?

Verificámos que, no que diz respeito à produção/omissão de clíticos, possivelmente uma área de interface, os bilingues português-espanhol têm taxas de omissão em espanhol superiores às dos monolingues. Pode, por conseguinte, considerar-se que há transferência da omissão típica do português para o espanhol.

A que se deve este fenómeno? E por que razão se dá neste sentido?

Uma possibilidade é que a omissão no espanhol seja de alguma forma resultante do contexto de imersão. Estas crianças vivem num contexto em que o português é língua dominante. Apesar de se encontrarem numa escola de língua espanhola, a língua do país é o português. Uma outra possibilidade é que este efeito seja determinado pelo estatuto das formas complemento: uma forma nula acarreta menores custos computacionais do que um pronome clítico. A não realização do objeto corresponderá à opção pela forma mais defetiva, tal como defendem Costa, Lobo \& Pratas (2013, 2014) e Pirvulescu et al. (2014). Num contexto em que o input pode ser ambíguo, as gramáticas iniciais vão optar por formas mais económicas. 
Os falantes bilingues distinguem os dois sistemas?

Apesar de haver maior omissão em espanhol nos bilingues do que nos monolingues, aparentemente os bilingues distinguem os dois sistemas. Não só há maior omissão nos bilingues em português do que em espanhol, como as taxas de omissão diminuem mais cedo no espanhol. Isto parece indicar que há distinção entre os dois sistemas, ainda que a estabilização dos contextos de omissão seja mais lenta.

Os falantes bilingues são sensíveis aos contextos morfossintáticos em que o objeto nulo é legítimo, i.e., há diferenças na produção de clíticos acusativos em frases simples, clíticos reflexos em frases simples e clíticos acusativos em ilhas?

Tal como nas crianças monolingues, há taxas variáveis de omissão em função dos diferentes contextos. A omissão é inferior nas condições com clíticos reflexos e, nos contextos de ilha, é ligeiramente inferior à de frases simples. Ainda que não tenhamos, de momento, uma explicação clara para esta diferença, é possível pensar que o contexto de ilha universalmente não é geralmente um contexto em que o objeto nulo (ou tópico nulo em línguas como o alemão) seja legítimo. O objeto nulo ‘defeito’ nas línguas naturais tenderá a ser uma categoria vazia do tipo variável e não de tipo pronominal nulo. No caso da aquisição do português, a questão é mais complexa. Não só há variação entre variedades do português (variedade brasileira vs. europeia) quanto ao tipo de categoria vazia objeto, como também parece haver alguma variação entre falantes da variedade europeia, visível. Ainda que a maioria dos adultos portugueses não aceite objetos nulos em ilhas, alguns falantes não os rejeitam. No estudo de Costa \& Lobo (2009), verificou-se que alguns adultos aceitaram objetos nulos em ilhas. Será preciso determinar, por conseguinte, quais são precisamente os contextos de ilhas em que os falantes aceitam/rejeitam a omissão e que fatores condicionam a variação entre falantes. Se o input das crianças em português não for completamente estável, espera-se que a omissão em português seja maior e se prolongue até mais tarde.

O percurso de desenvolvimento dos falantes bilingues é semelhante ao dos monolingues (no que respeita à produção de clíticos)? 
Como vimos, há omissão nos bilingues em português tal como acontece com os monolingues de português, mas há omissão no espanhol superior à que acontece nos monolingues. Há, portanto, diferenças entre bilingues e monolingues neste aspeto. Contudo, também se encontram semelhanças entre os dois grupos. Tal como os monolingues, os bilingues distinguem os diferentes contextos morfossintáticos: há mais omissão com clíticos acusativos em frases simples e menos com reflexos.

Podemos, assim, verificar que o desenvolvimento dos bilingues é convergente com a gramática alvo, mas aparentemente mais lento do que nos bilingues nesta área gramatical; as crianças de 5 anos já têm taxas mais baixas de omissão.

Verifica-se que os bilingues têm mais omissão do que os monolingues (e isto acontece aparentemente também em português). Este desenvolvimento mais lento pode eventualmente ser atribuído a um "efeito bilingue” (cf. Pirvulescu, Pérez-Leroux \& Roberge 2012; Pirvulescu et al. 2014), isto é, a um desenvolvimento mais lento desta propriedade gramatical nos bilingues atribuível a uma maior ambiguidade no input e a um input mais reduzido em cada um dos sistemas. É importante destacar que o desenvolvimento segue um percurso idêntico ao dos monolingues e que os adultos bilingues têm desempenhos correspondentes aos dos monolingues, ainda que o percurso de desenvolvimento possa ser um pouco mais lento.

Em síntese, verificamos que, no que diz respeito à produção de clíticos, os bilingues distinguem as duas línguas, uma vez que há diferentes taxas de omissão em cada língua. Há, portanto, alguma evidência para um desenvolvimento separado de cada sistema. Os bilingues distinguem os diferentes contextos morfossintáticos em que ocorrem os clíticos, seguindo um percurso de desenvolvimento idêntico ao dos monolingues: há taxas mais altas de omissão com clíticos acusativos em frases simples e taxas mais baixas de omissão nos contextos com reflexos.

Verificou-se, contudo, alguma influência de uma língua sobre a outra. O português, língua de objeto nulo, influencia o espanhol, língua com omissão de objeto em contextos mais reduzidos. Sendo esta uma área de interface e em que há alguma sobreposição entre os sistemas de cada língua, verifica-se uma extensão da forma mais defetiva nas gramáticas das crianças bilingues. Apesar de haver um desenvolvimento convergente com a gramática-alvo, os bilingues têm aparentemente um desenvolvimento um pouco mais lento do que os monolingues nesta área gramatical. 


\section{Agradecimentos}

Agradecemos às crianças, escolas, infantários e adultos que participaram no estudo, bem como a Stéphanie Vaz e Margarida Tomaz pela ajuda na recolha dos dados dos monolingues de português.

\section{Referências}

Avram, Larisa. (1999) Clitic omission in child language and Multiple Spell-Out. Poster apresentado no Gala 1999, Universidade de Potsdam.

Babyonyshev, Maria e Stefania Marin (2006) Acquisition of Romanian pronominal clitics. In A. Gavarró \& C. Lleó, eds. Catalan Journal of Linguistics 5. The Acquisition of Romance, pp. 17-44.

Campos, Hector (1986) Indefinite object drop. Linguistic Inquiry 17, pp. 354-359.

Castilla, Anny P. \& Ana Teresa Pérez-Leroux (2010) Omissions and Substitutions in Spanish Object Clitics : Developmental Optionality as a property of the Representational System. Language Acquisition 17 (1-2), pp. 2-25.

Costa, João \& Maria Lobo (2006) A aquisição de clíticos em PE: omissão de clíticos ou objecto nulo?. In XXI Encontro Nacional da Associação Portuguesa de Linguística. Textos Seleccionados. Lisboa: APL, pp. 285-293.

Costa, João \& Maria Lobo (2009) Clitic Omission in the Acquisition of European Portuguese: Data from comprehension. In A. Pires \& J. Rothman eds. Minimalist Inquiries into Child and Adult Language Acquisition: Case Studies across Portuguese, Berlin/ New York: Mouton de Gruyter, pp. 63-84.

Costa, João, Maria Lobo \& Fernanda Pratas (2013) Produção de Clíticos por Crianças bilingues e monolingues, In Textos Selecionados, XXVIII Encontro Nacional da Associação Portuguesa de Linguística, Coimbra, pp. 289-306.

Costa, João, Maria Lobo \& Fernanda Pratas (2014) Clitic production by Portuguese and Capeverdean children: omission in bilingualism. Probus. DOI: 10.1515/probus-20140015 .

De Houwer, Annick (2009) Bilingual First Language Acquisition. Bristol/NY/Ontario: Multilingual Matters. 
Duarte, Inês \& João Costa (2013) Objeto Nulo. In E. B. P. Raposo et al. (orgs.) Gramática da Língua Portuguesa. Lisboa: Fundação Calouste Gulbenkian, pp. 2339-2348.

Fernández-Ordoñez, Inés (1999) Leísmo, laísmo, loísmo. In I. Bosque \& V. Demonste, orgs. Gramática descriptiva de la lengua española. Madrid: Espasa, pp. 1317- 1397.

Fernández-Ordóñez, Inés (2012) "Dialect areas and linguistic change: Pronominal paradigms in Ibero-Romance dialects from a cross-linguistic and social typology perspective". In Gunther de Vogelaer \& Guido Seiler, eds., The Dialect Laboratory. Dialects as a testing ground for theories of language change. Amsterdam / Philadelphia, John Benjamins, pp. 73-106.

García Mouton, Pilar (1994) Lenguas y dialectos de España, Madrid: Arco Libros.

Gavarrò, Anna \& Noemí Fortón (2014) Person features and the acquisition of clitics. In C. Contemori \& L. Dal Pozzo, eds. Inquiries into Linguistic Theory and Language Acquisition. Papers offered to Adriana Belletti; Siena: CISCL Press, pp. 97-113.

Gavarró, Anna, Vicenç Torrens e Ken Wexler (2010) Object clitic omission: Two language types. Language Acquisition, 17 (4), pp. 192-219.

Genesee, Fred (1989) Early bilingual development: one language or two? Journal of Child Language 16, pp. 161-179.

Genesee, Fred, Elena Nicoladis \& Johanne Paradis (1995) Language differentiation in early bilingual development. Journal of Child Language 22, pp. 611-631.

Ilic, Tatjana \& Kamil Ud Deen (2004) Object raising and cliticization in Serbo-Croatian child language. Proceedings of GALA 2003, Volume 1, LOT, pp. 235-243.

Jakubowicz, Celia, Natascha Müller, O.-K. Kang, B. Riemer e C. Rigaut (1996) On the acquisition of the pronominal system in French and German, In Proceedings of the 20th annual Boston University Conference on Language Development. Somerville MA: Cascadilla Press, pp. 374-385.

Martins, Ana Maria (2013) Posição dos pronomes pessoais clíticos. In E. B. P. Raposo et al. (orgs.) Gramática da Língua Portuguesa. Lisboa: Fundação Calouste Gulbenkian, pp. 2231-2302.

Meisel, Jürgen M. (1989) Early differentiation of languages in bilingual children. In K. Hyltenstam \& L. Obler (eds) Bilingualism Across the Lifespan: Aspects of Acquisition, Maturity and Loss. Cambridge: Cambridge Univ. Press, pp. 13-40. 
Meisel, Jürgen M. (2004) The bilingual child. In T. K. Bhatia e W. C. Ritchie, eds. The handbook of bilingualism. Malden, MA: Blackwell Publishers, pp. 91-113.

Müller, Natascha e Aafke Hulk, A (2001) Crosslinguistic influence in bilingual language acquisition: Italian and French as recipient languages. Bilingualism: Language and Cognition 4 (1), pp. 1-21.

Nardelli, Marina Cestari (2015) Omissão de pronomes clíticos em crianças bilingues português europeu e espanhol ibérico. Diss. de mestrado. Faculdade de Ciências Sociais e Humanas, Universidade NOVA de Lisboa.

Paradis, Johanne \& Fred Genesee (1996) Syntactic Acquisition in bilingual children: autonomous or interdependent? Studies in Second Language Acquisition 18, pp. 1-25.

Pérez-Leroux, Ana Teresa, Mihaela Pirvulescu \& Yves Roberge (2008) Null objects in child language: Syntax and the lexicon. Lingua 118, pp. 370-398.

Pérez-Leroux, Ana Teresa, Mihaela Pirvulescu \& Yves Roberge (2009) Bilingualism as a window into the language faculty: The acquisition of objects in French-speaking children in bilingual and monolingual contexts. Bilingualism 12.1, pp.97-112.

Pirvulescu, Mihaela, Ana Teresa Pérez-Leroux \& Yves Roberge (2012) A bidirectional study of object omissions in French-English bilinguals. In Kurt Braunmüller \& Christoph Gabriel (eds.) Multilingual Individuals and Multilingual Societies. Amsterdam/Philadelphia: John Benjamins, pp. 171-188.

Pivulescu, Mihaela, Ana Teresa Pérez-Leroux, Yves Roberge \& Nelleke Strik (2014) Bilingual effects: exploring object omission in pronominal languages. Bilingualism: Language and Cognition 17.3, pp. 495-510.

Raposo, Eduardo Paiva (1986) On the Null Object Construction in European Portuguese. In O. Jaeggli e C. Silva-Corvalán (orgs.) Studies in Romance Linguistics. Dordrecht: Foris, pp. 373-390.

Schaeffer, Jeanette (1997) Direct object scrambling in Dutch and Italian child language, UCLA Dissertations in Linguistics, 17.

Schaeffer, Jeanette (2000). The acquisition of direct object scrambling and clitic placement: Syntax and pragmatics. Amsterdam: Benjamins. 
Serratrice, Ludovica, Antonella Sorace \& Sandra Paoli (2004) Crosslinguistic influence at the syntax-pragmatics interface: Subjects and objects in English-Italian bilingual and monolingual acquisition. Bilingualism: Language and Cognition 7 (3), pp. 183-205.

Silva, Carolina (2008) Assimetrias na aquisição de clíticos diferenciados em português europeu. Dissertação de Mestrado. Faculdade de Ciências Sociais e Humanas, Universidade Nova de Lisboa.

Stöber, Claudia \& Jürgen M. Meisel (2008) Omissão e realização de objectos na aquisição simultânea do alemão e do português do Brasil. In Cristina Flores (org.) Temas em Bilinguismo. Braga: Univ. do Minho/Centro de Estudos Humanísticos, pp. 61-88.

Tsakali, Vina \& Ken Wexler (2004) Why children omit clitics in some languages, but not in others: New evidence from Greek. Proceedings of GALA, 2, LOT, pp. 493-504.

Varlokosta, Spyridoula et al. (2016) A Cross-Linguistic Study of the Acquisition of Clitic and Pronoun Production. Language Acquisition 22.1, pp. 1-26.

Wexler, Ken, Anna Gavarrò \& Vicenç Torrens (2004) Feature checking and object clitic omission in child Catalan and Spanish. In R. Bok-Bennema, B. Hollebrandse, B. Kampers-Manhe \& P. Sleeman, eds. Romance Languages and Linguistic Theory 2002, Amsterdam: John Benjamins, pp. 253-270.

Yip, Virginia \& Stephen Matthews (2000) Syntactic transfer in a Cantonese-English bilingual child. Bilingualism: Language and Cognition 3 (3), pp. 193-208.

Yip, Virginia \& Stephen Matthews (2005) Dual Input and Learnability: Null Objects in Cantonese-English Bilingual Children. In James Cohen, Kara T. McAlister, Kellie Rolstad \& Jeff MacSwan (eds.) ISB4 Proceedings of the $4^{\text {th }}$ International Symposium on Bilingualism, Somerville MA: Cascadilla Press, pp. 2421-2431. 